\title{
Mood and force in defeasible arguments
}

\author{
Ryan Phillip Quandt ${ }^{\mathrm{a}, *}$ and John Licato ${ }^{\mathrm{b}}$

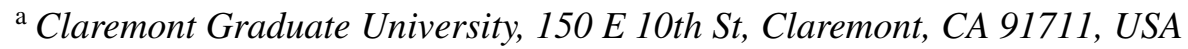 \\ E-mail: ryan.quandt@cgu.edu \\ ${ }^{\mathrm{b}}$ University of South Florida, 4202 E Fowler Ave, Tampa, FL 33620, USA \\ E-mail:licato@usf.edu
}

\begin{abstract}
Argumentation schemes bring artificial intelligence into day to day conversation. Interpreting the force of an utterance, be it an assertion, command, or question, remains a task for achieving this goal. But it is not an easy task. An interpretation of force depends on a speaker's use of words for a hearer at the moment of utterance. Ascribing force relies on grammatical mood, though not in a straightforward or regular way. We face a dilemma: on one hand, deciding force requires an understanding of the speaker's words; on the other hand, word meaning may shift given the force in which the words are spoken. A precise theory of how mood and force relate helps us handle this dilemma, which, if met, expands the use of argumentation schemes in language processing. Yet, as our analysis shows, force is an inconstant variable, one that contributes to a scheme's defeasibility. We propose using critical questions to help us decide the force of utterances.
\end{abstract}

Keywords: Force, mood, utterance, dialogue, defeasibility, presumption, burden of proof

\section{Introduction}

Say someone asks, "What is a vixen?" One hearer replies, "Vixens are female foxes," and another adds, "Vixens are just female foxes" or "Vixens are nothing but female foxes." The answers seem identical apart from changes in emphasis. Each answer tells us what a vixen is. As isolated utterances, their formal or logical structure looks the same however you parse it. But are they? Unless a speaker is careless with words or prone to popgun stresses, the adverb inflects the sentence's meaning. Our hearers may be surprised anyone needs to ask, uninterested in the question, trying to appear knowledgeable, reporting what they found on their phone, surprised by their discovery, responding to an insult - the list goes on. The phrases are used like a voice inflection or italics and share a similar range of uses. To our point, the phrases' weight almost entirely depends on the moment of utterance.

Adverbs, other grammatical devices, as well as vocal, written, or typed conventions are less than stable indicators of force. Context is notoriously drof, eluding forms and formulae. Some objects or events slip in unwanted, others fall out. Still, some explicit mark is needed for a hearer to recognize an utterance's force. Syntax is not enough since "just," "nothing but," and any other bits of language we dice up remain amenable to various forces, given the sentence, speaker, hearer(s), and setting. ${ }^{1}$ Open-textured terms remain (Hart [12]). So, again, hearers need some explicit mark, otherwise the frequent successes of daily conversation amount to guesswork. This chasm runs deep: apart from force, sentences give up meaning (Searle and Vanderveken [32]).

\footnotetext{
${ }^{*}$ Corresponding author. E-mail: ryan.quandt@cgu.edu.

${ }^{1}$ As you are likely well aware, we are referring to Quine's indeterminacy (Quine [29]).
} 
Nearly twenty-five years ago, Walton published Argumentation Schemes for Presumptive Reasoning, a major work on natural argumentation. Among its breakthroughs, Walton enounced how arguments are given and received in day to day conversation. His theory attuned scholars to the persuasive weight of natural arguments and evinced the benefit of taking these arguments seriously. Argumentation schemes formalized 'on-the-ground' debate and reason giving, how arguments evolve in conversation, and defined guidelines for assessing them. These schemes modeled ways to compute natural reasoning, too. In this book and others, Walton stressed that claims and questions are speech acts, and we must be sensitive to an utterance as speech and as an act. To do so, we must tend to the moment of utterances. He writes in an early chapter on presumption,

Hence the job of evaluating presumptive reasoning is inherently pragmatic, in that it depends on the particular circumstances of a given case, as far as these are known, to a given point. This context sensitivity and openness to revision is also characteristic of practical reasoning generally - a kind of reasoning that takes as its object an inherently variable situation unfolding in time (Walton [40, p. 41]).

In this paper, we aim to develop Walton's early insights. We expand on two claims that center on the act of uttering: (i) the relation of mood and force is a reason for the defeasibility of natural arguments and (ii) proposing schemes and asking critical questions help us define the force of an utterance. Walton's schemes lead us to the moment of utterance within dialogue - they must, in fact. In the same book, Walton writes, "The argumentation schemes and the matching critical questions set out a profile of dialogue... that defines what is correct or appropriate at any given point, in relation to the exchanges that surround it" (Walton [40, p. 14]). ${ }^{2}$ So schemes do not merely apply to utterances throughout a dialogue; they are used to interpret, and so make explicit, the meaning of an utterance within conversation.

Force presents "crucial challenges for pragmatics," Macagno warns (Macagno, Walton, and Sartor [23, p. 7]). Citing Dascal and others, he notes how the force of an utterance limits a reply's relevance (Dascal [6]), and so must be accounted for by his approach, how scholars need a view of speech acts that goes beyond sentence types and generic acts (Sperber and Wilson [33, p. 247]), which accounts for more than single utterances (Capone [5, p. xvii], Oishi [26, p. 343], Sbisà[31, p. 427]), and that utterances cannot be parsed by pairing grammar and illocutionary content (Strawson [35], Streeck [36], Kissine [16]). Macagno adopts an argumentative approach to relevance to address these concerns. Besides justifying relevance and marking strength, his approach assesses the "reasonableness" of an interpretation - a stake in the mood/force relation. A brief summary of his theoretical commitments sets up our analysis.

Utterances, for Macagno, are held as dialogical responsibilities (Brandom [3, pp. 160-162]), or "modifications of the social or dialogical status of the speakers based on the evidence produced (what is said)" (Macagno et al. [23, p. 2]). ${ }^{3}$ As a result, utterances license certain inferences, and so can be represented by patterns of material inferences (Walton, Reed, and Macagno [42, Ch. 1]). Yet Macagno recognizes the dead-end of pairing illocutionary content to grammar. An utterance is interpreted according to a speaker's intent to achieve a social effect based on reasons (Capone [4, pp. 446-447], Marmor [25, Ch. 2]). "More specifically," Macagno continues, "the starting point is constituted by the categories of joint (social) actions performed, proposed, and pursued by the interlocutors," that is, socially binding relations that result from a speech act (Macagno et al. [23, p. 8]). Depending on the categories, their status, and how they are used in interpretation, we must begin with an action or view utterances as certain kinds

\footnotetext{
${ }^{2}$ Italics added.

${ }^{3}$ See also Macagno and Walton [22].
} 
of acts. Macagno constructs the underlying intentions or conversational demands through presumptions fixed by a conventional relation between "utterance form and force" or systematic reasoning (Leech [17], Strawson [35]). An utterance within a dialogue is a move that changes the conversation in a certain way and can be classed by their subject or socially binding relation.

We can cope with force formally via argumentation schemes (MacCormick and Summers [24], Sartor, Walton, Macagno, and Rotolo [30], Summers [37], Walton, Sartor, and Macagno [43]). Such a scheme "states the form of premises and conclusion in each argument type" (Walton et al. [42, p. 9], Hasting [13]). One of the premises is a Toulmin warrant, a generalization or rule that links the premise(s) to the conclusion (Toulmin [39, pp. 89-95]). For example, 'If water is a liquid, then water is a natural element' is the warrant for the premise, 'Water is a liquid,' and the conclusion, 'Water is a natural element.' Warrants link the premises as conjunctions in the antecedent of the conditional with the conclusion as the consequent. So 'Water is a liquid' and 'A liquid is a natural element' change the warrant to the more satisfying 'If water is a liquid and a liquid is a natural element, then water is a natural element.' But argument types differ by their warrants. Argumentation schemes capture the differences. Macagno notes that handling an utterance's force widens these schemes' reach in daily conversation and humdrum acts (Macagno $[19,20]$ ) and he deals with force by framing utterances as dialogical goals, observing that we must go beyond the relation between grammar and illocutionary force (Macagno [20, p. 4]). We aim to further his project here, but not before spelling out what the relation between mood and force entails.

Our aims in this paper are (1) to argue that mood and force limits formal approaches to interpreting everyday speech, yet (2) motivate the use of argumentation schemes as a way to cope with that limit. What is this limit? Although sentences have a finite syntax, letters, and moods, their meanings are an open set. Speakers use old sentences for new meanings. Teasing out how mood and force relate explains their open-endedness. It also limits formalizing since meaning goes beyond regularities or conventions. Meaning comes from a speaker's intent, including the utterance's force, and this is why natural arguments are defeasible. The philosopher, Donald Davidson, helps us see as much. We begin with him, though, as we will see, he handles force obliquely and implicitly. Those of us who think mood and force can be formally dealt with will be unsatisfied with his pessimism. So we pivot. Mitchell S. Green offers a direct and explicit account that uses illocutionary validity to track force. But he missteps by pinning force to syntax and, as a result, undermines the defeasibility of everyday speech. More troubling, he obscures where meaning comes from. In the latter half of this paper, we show how argumentation schemes grant defeasibility and, through critical questions, handle linguistic acts by prompting, assessing, and reconstructing dialogue.

\section{Mood and force}

"Vixens are just female foxes" likens to an open-textured predicate insofar as its meaning depends on context, which covers propositional attitudes of speaker and hearer(s), their knowledge, and publicly available information. There is a "common ground," or shared understanding, and there is less than common information (Atlas [1, Ch. 2]). ${ }^{4}$ Argumentation schemes are a promising way for dealing with open-textured predicates. But the words or phrases, 'is just' and 'nothing but,' are not open-textured predicates since they are neither subjects or predicates. They relate the subject to its predicate, coloring with tone, emphasis, mannerism, gesture, and their ancillary kin. The same sentence may express many

\footnotetext{
${ }^{4}$ See also Macagno and Capone [21], Stalnaker [34].
} 
exclusive intents, such as sarcasm, seriousness, surprise, indifference, frustration, satisfaction. Intent changes meaning. To pick out the mood/force relation, we will narrow our object to identity statements.

'Is just' and 'nothing but' have a few grammatical roles. Both stress a word or phrase: 'is just' modifies nouns, adjectives, verbs, and adverbs, while 'nothing but' modifies nouns and copulas. ${ }^{5}$ Dictionaries do not specify what their "stress" amounts to, though we noted some uses earlier. We may find ourselves far afield from a sentence's usual meaning, but before charting this course, let us note properties of identities like "A vixen is a female fox." Dorr lists some (Dorr [9, p. 43]).

- Reflexivity: To be $\mathrm{F}$ is to be $\mathrm{F}$.

- Transitivity: If to be $\mathrm{F}$ is to be $\mathrm{G}$ and to be $\mathrm{G}$ is to be $\mathrm{H}$, then to be $\mathrm{F}$ is to be $\mathrm{H}$.

- Symmetry: If to be $\mathrm{F}$ is to be $\mathrm{G}$, then to be $\mathrm{G}$ is to be $\mathrm{F}$.

These properties only go so far in daily conversation. Annoyed at her inquisitive friend, someone may say, "A vixen is just a vixen." Are the vixens the same? Logically and on paper, yes, but the repetition changes how the hearer hears the word. It turns out a vixen is something the annoyed friend does not care to know about. 'Vixen' and 'vixen' look (nearly) the same, yet the intent behind the words comes in the repetition, along with tone, facial expression, gesture. So much, then, for reflexivity in Dorr's list. If the repeated names differ, transitivity also breaks down since a property of one may not be shared. Symmetry tracts more loosely. Subject differs from predicate, though to be one is to be the other. When qualified, we can approximate sameness. 'Vixen' and 'vixen' are the same word with differing uses.

Set vixens aside for an actual case. In an advice column from The Washington Post, a woman wrote in for her anxious sister's sake. The sister kissed someone other than her boyfriend after too many drinks. A cousin witnessed the kiss and, she fears, told other family members. Now she must bring her boyfriend to a family wedding and cringes over what someone may say to him. Carolyn Hax advises,

The only way she will feel less anxious is if she gets out from under the weight of her secret, for good. Either she tells her boyfriend; breaks up with him and thereby renders the secret moot; or finds a way to release herself of the guilt and just accept what she did as the kind of stupid thing humans do and forgive herself for it (Hax [14]). ${ }^{6}$

Now her advice fits an argument from two-person practical reasoning (Walton [41], Walton et al. [42]):

Premise 1: $X$ intends to realize $A$, and tells $Y$ this.

Premise 2: As $Y$ sees the situation, $B$ is a necessary (sufficient) condition for carrying out $A$, and $Y$ tells $X$ this.

Conclusion: Therefore, $X$ should carry out $B$, unless he has better reasons not to.

$X$ is the sister and she tells Hax through the woman who wrote in. Hax sees the situation and offers three ways to achieve the sister's goal - acts to obtain an end. But this parsing assumes a dubious reading of 'just accept.' The third option ("finds a way to release herself of guilt") seems to encompass the first two and "just accept" seems to be the goal. Or "just accepting" obtains the end. The means and goal are less than clear. Where we place the stress changes the argument. We will come back to this example in a moment. ${ }^{7}$ Suffice to say, critical questions help us interpret the force(s) of the utterance, and so face the natural argument. Coupled with a principle of charity, ${ }^{8}$ argumentation schemes help us cope with

\footnotetext{
${ }^{5}$ See $O E D$, entry 6, for 'just', and entry P1.a. of phrase 'nothing but,' under 'nothing.'

${ }^{6}$ Italics added.

${ }^{7}$ And we will expand on possible interpretations, too.

${ }^{8}$ To be developed in a later piece.
} 
the mood/force relation. We will return to this dialogical use of argumentation schemes for computation after we propone a theory.

\subsection{Theory}

1. A model and definitions. An idealized model of communication marks the requirements for a hearer to successfully understand a speaker (Davidson [8, pp. 100-109]). Within this model, we will define mood and force pro tem. This is a model for picking out requirements for communicating; this models not what happens in minds, nor self-aware expectations. Speakers and hearers get along without a mental map akin to a dictionary and grammar. The model is ideal, yet illuminates starting definitions. For an utterance to have a specific force, a speaker must intend her act to do something, signal that intent fittingly, and the hearer perceive it. ${ }^{9}$

Say in every linguistic exchange a speaker has a theory for how to speak so that a hearer will rightly hear. A hearer has a theory for how to make sense of a speaker's words. The theory of each splits into (i) prior theories, ways of interpreting an utterance before the uttering, and (ii) passing theories, which form during the occasion of utterance (how the words are voiced and heard in the moment). Prior theories consist in knowledge of grammar, idioms, definitions, past uses or misuses. A hearer anticipates a speaker and the speaker a hearer according to their prior theories. Passing theories are how this hearer interprets this speaker's utterances. If a speaker slips, saying, "A vixen is a female sox," yet the hearer hear 'sox' as 'fox,' passing theories converge without loss. In nearly every exchange, tone, word choice, situation, gesture, and stress color a speaker's utterance in unique ways. A hearer may not always be sure whether they heard a hint of irony, sarcasm, or humor. Sincerity may be hard to detect as well. Past uses do not prepare us for one-off utterances. Maybe the speaker never has and never will again say 'sox' instead of 'fox' after the embarrassment. Converging passing theories, not prior ones, is all communication requires (Davidson [8, p. 96]).

We define mood and force from this one requirement for communication: a hearer must pick up a speaker's intent. Does mood fall within prior theory? A dictionary entry claims no: the form of the verb sets the range of meanings. Mood is the form of a verb that expresses a fact, a command, a question, a wish, conditional, potential. ${ }^{10}$ So a verb is indicative, imperative, interrogative, optative, subjunctive, exhortative. An utterance expresses through the form of the verb, the mood. On the ideal model, however, verb form differs from an utterance expressing fact, command, question, wish, conditional, or potential. Only the latter comes through passing theories.

Passing theories are less stable and sure than prior ones. Force sits squarely in passing theory, as some definitions bear out: "The real import or significance (of a document, statement, or the like); the precise meaning or 'value' (of a word, sentence, etc.) as affecting its context or interpretation."11 Though force concerns utterances for us, not documents or statements, a contract "taking effect" holds our sense. The definition notes that force comes from the moment of utterance, which tracks the model. If meaning comes through the convergence of passing theories, force does not merely inflect a prepackaged meaning. Force fixes mood for a given utterance. Yet it is hard to imagine any verb form

\footnotetext{
${ }^{9}$ This is not a complete definition, but a minimum from which we argue. There are external conditions that may frustrate that intent, for example. But it does not rely on the speaker alone: a speaker must express that intent in a way their hearer will recognize.

${ }^{10}$ See $O E D$, entry for 'mood', n.2.

${ }^{11} O E D$, 'force', n.1, entry 9.
} 
lending itself to any force with no rhyme or reason. Word use cannot be arbitrary. Our model prompts us to zero in on how mood and force relate given an utterance.

2. Requirements for a theory. Davidson nears force with a theory of mood. An adequate theory meets three requirements, he writes (Davidson [7, p. 115-116]). The theory relates indicatives to other grammatical moods. 'I do not know what a vixen is,' 'What is a vixen?' and 'Tell me what a vixen is' differ in mood, yet 'what a vixen is' means the same (at least, roughly) across sentences. A theory of mood must capture this semantic core, that is, how the same words retain their meaning across moods. At the same time, these sentences may have the same force when eliciting a definition from a hearer. The speaker says one of them to express their intent. So a theory of mood relates indicatives to interrogatives and imperatives, yet their relation does not fix force.

An adequate theory of mood also ascribes meaning to one utterance that is not shared with an otherwise similar utterance in another mood. Take 'Tell me what a vixen is' and 'I do not know what a vixen is.' Their mood differs and so 'what a vixen is' shifts meaning when embedded. A theory of mood explains how the words are the same, while also noting a semantic change. Supposing their force is the same, their mood and meaning still differ, which we need to explain. Compare also 'A vixen is a female' when spoken of a fox, then of a woman.

The first and second requirements for an adequate theory of mood name our intuition that something basic and solid joins mood to force. Meaning is not arbitrarily bequeathed to sounds and signs. And the same holds for moods a speaker uses. Moods lend themselves to certain uses.

Last, a theory must be "semantically tractable" (Davidson [7, p. 116]): how it leads us to interpret utterances fits a larger working theory of meaning. Sentences cannot divorce from their utterances. Saying "A vixen is a fox" cannot entirely depart from the words' meaning on a page. Those words still contribute to an utterance's meaning. We will assume here that assigning truth conditions to an utterance gives meaning. ${ }^{12}$ For Davidson, Tarski's theory of truth can be repurposed (Tarski [38]). A T-sentence results from each sentence $s$ such that it supplies meaning: ' $s$ is true if and only if $p$,' or 's means $p$ ' (Davidson [7]). We will not defend recycling Tarski's theory for meaning, but only assume that meaning amounts to the truth conditions of an utterance. A theory of mood, then, tracts meaning when conforming to assigned truth conditions.

But the last requirement conflicts with the other two. An adequate theory of meaning stuts on paradox. If specifying truth conditions tells us meaning, imperatives and interrogatives seem meaningless. 'Define vixen' and 'What is a vixen' are not governed by truth-functional operators since they lack truth values. The first pair of requirements prompts us to define a non-truth functional operator to relate sentences across moods, yet our theory of meaning bars that option (Davidson [7, p. 116]). Put again, non-indicatives lack truth values so they must have a distinct operator, but the only operators available are truth-functional. We are left with a stark choice: non-indicatives lose either meaning or mood.

3. Mood's obstacles. It is tempting to think mood can be more or less dealt with - force evades us. Since mood concerns verb form, there are mechanisms to parse moods. But this belief strips mood of meaning. Too automatic a parsing, that is, misses how mood changes an utterance's meaning. Such a process relies on syntax, but the above unmasks a boondoggle: pairing mood with bits of syntax to gain meaning. Grammar does not suffice for explaining sentence mood. The switch from indicatives to nonindicatives pushes us to drop meaning, add a type of meaning, or reduce non-indicatives to indicatives. Dropping meaning leaves us to ask how non-indicatives 'make sense' to a hearer. We also have the burden of explaining how the same words lose their meaning when put in non-indicative sentences. And

\footnotetext{
${ }^{12}$ No doubt, a large assumption. Even if you disagree, the approach to mood and force below can be tailored.
} 
where does the force of our words come from? How does a grunt differ from an articulated command? We should aim to preserve meaning, the same type of meaning across moods, otherwise words lose one for the other. Meaning is hard enough to grapple with as a concept. Reducing non-indicatives to indicatives, on the other hand, risks the semantic uniqueness of non-indicatives. Mood signals a cul-desac.

Circle back to the claims that the only operators at hand are truth-functional and that meaning comes from uttering words. Prior theories only get a hearer so far when making sense of a speaker. How sentence mood contributes to an utterance's meaning comes after successful speech. A speaker may break from usual syntactic forms to describe, command, or question. Still, an explicit mark tips a hearer off to a speaker's intent. Say we put grammatical moods with their usual syntax in speaker's and hearer's prior theories. 'What is a vixen' is an interrogative, while 'Tell me what a vixen is' is an imperative. When does a hearer rightly hear the first as a question, the second as a command? This cannot be decided apart from the moment of utterance. If someone says, 'Tell me what a vixen is,' in reply to, 'What did Jack ask,' the first sentence is not a command. But, as we will argue, the asymmetry between utterance and its sentence resolves mood's paradox.

Some may deny our troubles. When a speaker, frustrated, says, "A vixen is just a vixen," his words have assertoric force with the aim of ending the conversation. The words' force is illocution, deniers reply, while the aim is perlocution, or an intended effect. Our problems conflate them. Mood is bound to words in an utterance, which can be put to many, open-ended, and various purposes. ${ }^{13}$ We are not rejecting this distinction. Utterances have many purposes, some of which do not tamper with meaning. But this objection rightly picks out that our view denies the exhaustiveness of grammatical categories for mood. That is, mood is not entirely prepackaged: it contributes to meaning from the force of the words in its mold.

The difference between illocution and perlocution places mood within dialogical schemes. Once we drop prepackaged mood, we see that the aim of the utterance, or larger purpose of a dialogue, can be served by almost any mood. That is one side. Mood and force also match in various ways, and so the force of words is not given by mood. Without deciding force, though, we cannot decide how a sentence furthers an aim or dialogue. And if that is undecided, we are at a loss which scheme applies. Mood cannot be dealt with apart from force. Successful communication demands the convergence of passing theories, nothing more. And so mood without force insulates a theory of syntax, a syntax of grammar textbooks instead of natural language, or mood records past regularities. But all of this content falls within prior theories, and so is of limited help with utterances. By clarifying how force pairs with mood, we take a required step in using (and automating) argumentation schemes for everyday conversation.

Davidson's model and the requirements for a theory of mood layer defeasibility. For Walton, defeasible arguments are given in a setting of limited knowledge. Conclusions may be withdrawn or modified if premises turn out to be false with more information. Those discussing accept claims provisionally. Even when a hearer cannot think of how to oppose, he may resist a conclusion. Walton's reasons for defeasibility assume the hearer has heard an utterance as a claim. The import of the speech act has been noted. Davidson's model assigns the act of uttering as a reason for defeasibility. In other words, natural arguments are defeasible because they are given in everyday language, which only requires the convergence of passing theories for a speaker to communicate to others. But this requirement also means on-the-ground interpretations are fragile. A speaker may misspeak or a hearer mishear, yet not realize

\footnotetext{
${ }^{13}$ See Green [11, p. 291, ft.]. Also, Austin [2, pp. 99-103] and Dummett [10, p. 209].
} 
until later in the exchange. An utterance is an act and, like any act, it is not always obvious why an agent acted or what was meant by it.

More is at stake than understanding, though, since speakers and hearers often get by. Mood and force effect burden of proof and presumption. When a speaker makes a claim, they shift the burden of proof to the hearer, who shifts the burden back with a question or by rejecting a premise. An answer to the rebuttal gives the burden back, and so on, until the give and take ends. The burden does not come from the claim singly, but from the act of asserting the claim. Since an indicative, imperative, and interrogative have various forces, each can be used in dialogue to put forward a claim. And forces other than assertion can move debate forward according to a dialogue's type and goals. ${ }^{14}$ A presumptive inference requires theorists to interpret an exchange for the sake of constructing the inference - namely, to identify the force of the utterance(s) within their setting and then detail their claims. The inference is presumptive because it is rarely on the surface of daily conversation. Nor is it often clear to those outside the conversation why the burden in a dialogue shifts or fails to. Again, we are after the convergence of passing theories.

Besides assuming, presuming, and interpreting force, argumentation schemes help us make the force of an utterance (or utterances) more explicit. They help after an exchange and during one. A transcribed dialogue may mask the force a speaker's utterance. Schemes uncover possible intents. More, schemes frame various claims and uncover ways the inference shifted throughout the conversation. In one part, a speaker's claims may neatly fall in one scheme until a hearer exposes a weak commitment, then the hearer backpedals toward another inference. During an exchange, schemes not only guide speakers to supporting reasons or prompt hearers with the right questions; critical questions also prompt a speaker to be more explicit about the claims made, that is, about how these claims are being made. What is the force of the utterance by which a speaker claims? What is the mood of the sentence used? How does force and mood together shape the claim? The answers to these questions come from the exchange itself, and so cannot be decided beforehand in theory. We return to schemes and Hax's advice after defending this last remark.

\subsection{Setters and indicators}

Word choice and syntax effect the mood of a sentence and the force of saying that sentence. An explicit mark tips a hearer off to a speaker's intent, and the mark may be a word. The same words differ in how they inform the mood of a sentence. We cannot be too quick to generalize mood or force from a phrase or a bit of syntax. Austin observed that 'Go' does the same as 'I order you to go. ${ }^{15}$ Assuming that these sentences do not report an internal state (id est, my wanting you to make it the case that you go), they lack a truth value. So they seem to lack meaning, while 'He orders you to go' does not. A theory of mood parses these differences and explains how non-indicatives are meaningful from word choice and syntax (though not exclusively). So embedding serves nicely as a site for theory.

Scholars misstep when they look past truth-functional operators to bring in non-indicatives. They miss how mood and force effect meaning, that is, how the act of uttering makes a sentence meaningful. Compare 'I order you to go' with 'He orders you to go.' The referent of 'you' changes with the subject, though meaning should hold (at least, to a degree) since the embedded phrase, 'you to go,' has the same function. But the first, when commanding, lacks a truth value. The sphinxine change from first person to third signals a change in force. 'I order' commands and the embedded phrase tells what is commanded. It does the same as 'Go.' By contrast, the third person sentence does not. It can be glossed, "He orders you

\footnotetext{
${ }^{14}$ For a recent discussion of relevance in argumentation schemes, see Macagno [19].

${ }^{15}$ For Davidson's discussion of Austin, see Davidson [7, pp. 117-118].
} 
to make it the case that you go.' Likely, the speaker asserts and, if their assertion is true, the embedded phrase commands. These sentences differ in meaning, not in kind. Looking for other types of meaning (or dropping meaning) overlooks how they remain acts of speech.

If force marks a special set of truth conditions, embedding 'you to go' loses its ordinary meaning. Its truth values in 'Go,' 'I order you to go,' and 'He orders you to go' differ entirely. But let's not step off well-worn semantic tracks. Without ordinary meaning, ordinary uses are lost. We cannot explain how 'Go' achieves the same as 'I order you to go' or how either logically relate to 'He orders you to go.' A mystery surfaces. Note, too, that a special set of truth conditions cleave force and mood, whereas our model should prompt us to bring them closer together. We are otherwise left to relate truth conditions of indicatives with another set from non-indicatives - an odd dualism. Davidson stresses, "The problem is adventitious, since what is special about explicit performatives is better explained as due to a special use of words with an ordinary meaning than as due to a special meaning" (Davidson [7, p. 117]). So word meaning holds, yet the use of words differs. This is another way forward that more closely pairs mood and force. How, then, can word meaning hold, yet force effect meaning? To answer this, we need a theory with the right variables.

1. Mood setters. How embedding works in indicatives helps us see how non-indicatives work (Davidson [7, pp. 118-119]). "Jones asserted that it is raining" can be handled as two utterances: 'Jones asserted that' and 'it is raining.' In the first, the speaker asserts that Jones asserted; the embedded phrase is not asserted, but is the content of Jones' assertion. Key is the role of the demonstrative, 'that,' which refers the first utterance to the second. ${ }^{16}$ The utterance becomes 'Jones made an assertion whose content is given by my next utterance. It is raining.' Its truth conditions are specified, 'Jones asserted that' if and only if Jones asserted that in a given time and place.' The demonstrative refers to the content of Jones' assertion. An adept of Jones' language recognizes what must be the case for his utterance to be true. So if Jones asserted truly, and it is not raining on us, then Jones is somewhere else. The referring 'that' marks a logical conjunction, too, since if either utterance is false, so is the whole. This analysis is what we mean by a sentence's ordinary meaning, which non-indicatives preserve (to a degree).

Davidson leaves indicatives alone in his theory of mood, but this default is more provisional than he lets on. Indicatives have truth-functional operators, so their mood is meaningful. An indicative asserts among other acts. A speaker may declare, "A vixen is a female fox," and a confused hearer may repeat the sentence as a query. Force concerns how a sentence is used so that, when a speaker inquires, the sentence has a special use. Still, how a speaker uses a sentence changes its meaning. The same indicative asserts and queries, and an assertion and a question differ in meaning (given the requirements for an adequate theory of mood). Leaving indicatives alone for too long leaves these changes untouched because force does not leave indicatives' mood intact. A theory must cover them. When an indicative is spoken to query, it seems to drop its truth value unless our theory explains otherwise. How does Davidson's theory deals with this observal?

If indicatives are a provisional default, Davidson's definition of non-indicatives must be reworked. Put aside scruples for now to get a better sense of his perspicacy. Davidson defines non-indicatives as "indicative sentences plus an expression that syntactically represents the appropriate transformation," which he calls a mood setter (Davidson [7, p. 119]). To make headway, we will explore mood setters. Recall "You are going" to command, then to assert. Both uses share truth conditions. They differ from a transformation, which describes how a non-indicative relates to its indicative kin. The word, 'transformation,' theorizes what the special use of words in non-indicatives effects. Utterances, not sentences, fix

\footnotetext{
${ }^{16}$ This is how the utterance of the sentence is analyzed, not the sentences isolated from an uttering of them.
} 
truth conditions, so a speaker does not break an indicative from its mold when uttering a non-indicative. Said again, a speaker does not twist a ready to hand indicative. Meaning comes from uttering the sentence. So when a non-indicative is spoken, an indicative transforms in theory. A mood setter marks a change in the sentence, evinced by verb, word order and choice, punctuation or pause, tone, gesture, stress. The uttered sentence has an indicative core, so non-indicatives retain meaning.

A speaker does two simultaneous acts when saying a non-indicative. She says an indicative and a mood setter. Like the demonstrative in 'Jones asserted that,' a mood setter refers to an indicative, changing the truth conditions. The speaker does not assert $x$ when Jones asserts $x$. By embedding $x$, the truth conditions change. Mood setters, likewise, change by referring to the indicative core. Davidson explains that a mood setter "behaves like a sentence an utterance of which refers to an utterance of an indicative sentence" (Davidson [7, p. 120]). Though mood setters function like sentences, they cannot stand alone, bereft of their own truth conditions, syntax, and logical structure. A mood setter holds or fails to hold relative to an utterance of a sentence. With demonstratives, the truth conditions of the embedded phrase and the embedding one conjoin. Their truth value stands or falls as one. Not so with mood setters. They are not logically conjoined with their indicative core so that they form two conjuncts. Rather, the utterances, taken as a whole, lack a truth-functional operator. The mood setter holds or fails to hold, and the truth conditions of the indicative core thereby transforms or not.

There is a catch, one that Davidson's ideal model prepared us for: a mood setter must be an explicit mark, yet it cannot be formalized into a necessary or regular constant. Two distinct speech acts occur since we can explain how sentences in non-indicative moods use an explicit sign to represent a transformation of the indicative. Yet the two acts are entwined. A mood setter is not a word or sentence, but parasitic. It is syntactic without being a fixed piece of syntax. Nor can saying a mood setter guarantee the sentence has a certain mood. "There is broccoli on your plate," while indicative on surface syntax, can be imperative or interrogative. Force unhinges mood from an essential symbol. And so a mood setter holds from the convergence of passing theories between speaker and hearer.

A mood setter systematically represents non-indicative moods through syntactic effects. This notion is not blind to the force of speech, but framed with respect to force. Davidson couples mood with force in his setters, observing, "the concept of force is part of the meaning of mood" (Davidson [7, p. 121]). It is worth pausing on how this is so. An utterance's force emerges when indicatives transform into non-indicatives because truth conditions alone give force meaning. In principle, any sentence can have any force; however, force has a semantic range from the syntactic effects that reveal it. Force is inert or absent if an explicit, determining mark is not given. An utterance has a given force from certain syntactic effects, otherwise it is null. ${ }^{17}$ But indicatives can be used to question or command. How is this rightly heard by a speaker? Presumably, mood setters are not spoken. Interrogatives may command, imperatives assert, so how does a mood setter lock grammatical categories while covering the syntactic effects marking various forces?

As they stand, mood setters comprise too much. On Davidson's account, they are spoken, enact a transformation, and mark the transformation. The problem is that force swings freely of mood, yet mood setters mark a transformation resulting from force that limits the scope of the utterance's force. We can explain the hiccup. Davidson uses mood setters to bridge the gap between an utterance and a sentence, which may be why they are so uncanny. They behave like a sentence but are not sentences; they are syntactic, not a piece of syntax, an explicit mark, but not easily formalized. Mood setters occupy the gray area of theory and everyday speech, which is why they are so attractive. Davidson's theory of mood

\footnotetext{
${ }^{17}$ Assertion falls out of Davidson's account.
} 
has deep sympathies with Walton's views on argumentation. They are after the ins and outs of actual conversation. But mood setters seem indifferent to force, on one hand; on the other, they result from, effect, and limit force. That is, a speaker voices them and, by doing so, transforms the words spoken and fixes their force. Theorists should say more on how mood setters relate to force.

Someone says, "A vixen is just a female fox." Now, conventional wisdom leads us to believe this is an indicative sentence that asserts. The adverb may stress harmlessly if so. And, no doubt, an indicative has many uses. But force changes when, for example, someone says this sentence to reply to someone else who persists in thinking that 'vixen' means more. Suppose the speaker is an expert on word meaning and says this sentence as the final word. Then, the speaker commands and, if so, 'just' may be the explicit mark for the speaker's intent. Is it a mood setter? Yes, if it marks the transformation of an otherwise indicative into an imperative. The word marks the speaker's intent, the hearer takes it as such, and so the utterance commands. But, no, the adverb is not a mood setter since a single, stressed word does not make it a mood setter. How could we know? Our example could be an indicative despite, but the act of uttering transforms, given aligned passing theories, not merely speaking a word in a sentence. The speaker intends, expresses his intent, and a hearer perceives as much, but neither intent, hearer's perception, a word or phrase, nothing theorists isolate in an utterance make a mood setter.

This is a theory of mood, not force, but Davidson has an eye to force. This is a reason for hesitancy. "A vixen is just a female fox" looks indicative. While surface grammar may deceive, speakers, hearers, and theorists cannot neglect it. Mood setters seem to preserve tried and true grammatical categories by leaving indicatives alone and letting force swing free; at the same time, they minimize syntactic restraint on mood, force, and meaning. Mood setters, after all, are a non-conventional, non-constant, explicit mark. Successful communication aligns passing theories with varying aid from prior ones ('varying' being the key word here). A persuasive theory of mood explains how traditional grammatical categories play a role in the meaning of utterances (more generally, how words contribute to meaning) without bowing to them entirely. It must track semantics as well as explain how force changes meaning. If mood setters are underdetermined, though, we are in danger of applying the concept arbitrarily. The theory illumines less than it should. To avoid this, we need a more robust sense of force and how force relates to mood.

If Davidson is right, (i) we cannot attach a constant mark to an utterance's force, (ii) nor utter some constant for our utterance to assert rather than command or question. Both are non-starters since force concerns the use of words, not the words themselves. Our theory of mood and force begins and ends with the requirement for a hearer to rightly hear a speaker: the convergence of passing theories. Defeasibility and presumption have a crucial role here, as Walton, Reed, and Macagno note (Walton et al. [42, pp. 2-3, 32]). Some critics miss Davidson's argument and insight. ${ }^{18}$ Davidson gives a theoretical basis for the inherent defeasibility of on-the-ground natural reasoning from the elusiveness of everyday language. The more we understand why our day to day exchanges are defeasible and revisable, the better we involve AI in those exchanges. Davidson's stance does not upend formalizing projects. We can theorize force even if we cannot attach a symbol to an utterance's force with guarantee. He warns us against prematurely declaring success.

2. Force indicators. A pivot to force, then. Green agrees with Davidson that there are no constants that, when uttered, assert rather than command. He calls them strong illocutionary force indicator devices (or strong ifids): "an expression any utterance of which indicates that an associated sentence is being put forth by a speaker with a certain illocutionary force" (Green [11, p. 218]). Said again, a strong ifid pairs

\footnotetext{
${ }^{18}$ In their defense, Davidson implicitly relies on arguments given elsewhere and writes densely in his own style.
} 
a sentence with a force when spoken. This ifid is strong because its explicit mark engenders a given force when uttered. If

$\Delta_{-}$

stands for the function of illocutionary force and $A$ stands for a sentence, then

$\Delta(A)$

is an utterance of the sentence, $A$, with the defined illocutionary force (Green [11, pp. 218-219]). ${ }^{19}$ Theorists symbolize force such that the utterance of that symbol confers force. Coupling the symbol with a sentence in the act of uttering, a speech act occurs.

Strong ifids do not work. If they did, 'serious' speakers would not differ from jokers, story-tellers, actors, politicians, and other 'non-serious' speakers. All of them can use the strong ifid to enhance their utterances, yet a friend telling an event differs from an actor narrating from a stage. Not to mention that a symbol cannot guarantee a speech act occurs. Besides actors, jokers, and their kin, the scope of sentence use defies strong ifids. Saying, "I order you to go," does not ensure the utterance commands or that this sentence can only command. The words can be said without commanding; for example, as a reply to the question, "What did Jack say." Someone may add, 'seriously' or 'honestly' or 'I mean it,' without being serious, honest, sincere, or intending their hearer to think them so. A symbol cannot confine the meaning or force of an utterance in this way. Meaning comes from the convergence of passing theories, though prior theories form some of the content, beliefs, and expectations. ${ }^{20}$ This single requirement brings us into the complexities of the most mundane exchanges.

In mundane conversation, that is, ambiguity is ubiquitous. ${ }^{21}$ An insecure hearer may often wonder, 'Was that an insult?' A theory of force should preserve this ambiguity, otherwise it overdetermines (misses) an utterance. This is a problem for strong ifids because they both secure and confine the force of an utterance. Given the device, an utterance has this force as opposed to that force, which skews uttering and the sentence uttered. This is off. Force comes from the act of uttering, not a symbol. Refetch "A vixen is just a female fox." Strong ifids fix force and disambiguate a sentence prior to its use. But the same words assert, command, or question, and adding another mark does nothing more than 'I assert that.' Theory cannot align prior theories with passing ones, yet that is what strong ifids presume. If there are unresolved ambiguities in an utterance, a theory of interpretation should retain them until a speaker clarifies. With force, hearers can always ask about sincerity, trust, transparency, beliefs, and intentions, and so an utterance's force never fully surfaces. Handing a speaker new symbols cannot evade such questions.

Green disagrees with the view that no constant marks an utterance's force. He proposes a way to save strengthened moods: weak illocutionary force indicating devices (weak ifids). This indicator concerns a speaker's commitments based on an utterance so is couched within illocutionary validity. Validity centers on a speaker, $S$, and a sequence of force/content pairs,

$$
\left\langle\Delta_{1} A_{1}, \ldots, \Delta_{n} A_{n}, \Delta B\right\rangle
$$

\footnotetext{
${ }^{19}$ We can safely ignore Green's added claim that any sentence containing the above pair is an utterance of it.

${ }^{20}$ Not in a fixed manner.

${ }^{21} \mathrm{~A}$ degree of indeterminacy, that is.
} 
such that a speaker's pairings are valid if and only if a speaker is committed to a given sentence under a given mode, then the speaker is also committed to another sentence under the same mode (Green [11, p. 228]). To be clear, a mode is not a mood: a sentence has a mood while a commitment to a sentence has a mode. So 'A vixen is a female fox' is indicative and, if asserted, a speaker is committed to the sentence assertorically. If that holds, the speaker is also committed to the sentences, 'A vixen is a female' and 'A vixen is a fox' in the same way. A speaker need not say any implied commitments, though hearers expect consistency of a speaker's beliefs across force/content pairings. Green's ifids are weak because they assume a sentence was uttered with some force. They do not usher force in.

If a sentence, $A$, joins with any mode, then that sentence has a certain force. The new and contentious variable is

$$
f_{\Delta},
$$

which stands for the force associated with connective,

$$
\Delta_{-}
$$

The variable joins mood and force in this mechanism: mood carries a certain force through the speaker's commitment expressed by uttering a sentence (id est, the mode in which it is uttered). A weak ifid is a valid inference, one that infers force from a mode:

$$
\frac{f^{\prime} \ldots \Delta(A) \ldots}{f_{\Delta} A} \text {. }
$$

Assuming a mode/content pair has a force, then the utterance has this force, be it asserting, commanding, or questioning. Since mood does not fix mode, a speaker may utter an indicative sentence without asserting. If a speaker is committed to 'A vixen is a female fox' as a supposition, then its force differs. Green's theory approaches force from belief and ascribes beliefs conditionally. A weak ifid does not guarantee an utterance has a certain force or that a speech act has happened. It signals that, if there is a speech act, the speaker must have a certain belief or type of commitment, and not exclusively.

A few observals are in order. If a speaker is committed to the claim that a hearer should tell her what vixens are, then "Tell me what a vixen is" commands. This does not mean that the speaker's beliefs are enough to fix force. A speech act can fail with or without the proper belief. So, assuming the uttering enacts, saying the imperative above has imperatival force. Some conditions for the act are the proper belief, sincerity, and intent. Others are outside the speaker's control, such as the hearer recognizing the speaker's intent and hearing the words correctly. Green closely parallels an utterance's force with the beliefs of a speaker. If the utterance enacts, and so commits a speaker to something, the utterance has a certain force and commits the speaker to certain claims. But the output is minimum since an utterance may have other forces, other modes, and more than one purpose. In this way, too, the indicator is weak.

Green thinks some English expressions are weak ifids. ${ }^{22}$ He gives an example: say 'as I claim' parenthetically and, if a speaker is committed to anything at all, they are committed assertorically (at least), and so assert. Other forces may be in play, no doubt; syntax hafts a minimum. A speaker asserts, along with any other force or point at work. "A vixen, as I claim, is a female fox" commits a speaker to the belief that a vixen is a female fox, if spoken seriously. In support of this view, Green gives a thought

\footnotetext{
${ }^{22}$ If so, cataloguing these devices would be a sentential basis for programming and generalizable over a group of speakers.
} 
experiment (Green [11, pp. 235-236]). Add to our language the verb, 'swave,' which means the same as 'to wave' except it also expresses assertoric commitment when it has any force. Set in a conditional, a speaker commits: "If John swaves his hand, then Mary stops her car." This is a complex speech act. The whole entailment is asserted, as is the antecedent, and so the speaker is committed to the consequent by implication. Since words can be weak ifids, language can be tied to a force.

Note that parentheticals differ from a dependent phrase. Embedding a sentence with 'I claim that,' Green concedes, need not assert. It is not a weak ifid (Green [11, p. 234]). Someone may say, "I assert that grass is green," hypothetically. By contrast, Green believes no one will utter a parenthetical seriously without asserting. To utter these words seriously is to assert, and so force surfaces with these words. But his example suggests we should not assume as much. Let us explain.

Green notes a counterexample that "we could learn to live" with: 'It is not the case that John swaved his hand' ascribes an inconsistency to the speaker (Green [11, p. 236]). This problem also occurs in 'It is not the case that John waved his hand, as I claim.' Green avoids blunt contradiction by separating the truth conditions of the parenthetical from the rest of the sentence. This sounds like Davidson's mood setter, which does not conjoin with the sentence. For Green, the parenthetical has unique truth conditions, yet functions on the rest of the sentence through a weak-ifid elimination inference. Its truth conditions depend on whether an assertion is made. If so, the weak ifid ascribes assertoric force to the utterance and the respective belief. Here is the uncanniness: 'as I claim' is syntactic and more than syntax because it is the direct expression of a speaker's (serious) intent. Where does his confidence in spoken parentheticals come from?

To us, Green mistakes ambiguity for transparency. Look at his counterexample. If the parenthetical ascribes a belief, the utterance seems to conflict. Green assures us it does not if the negation is stipulated, not asserted. While right, there is no good reason to say so except avoiding contradiction. To see this, here is another way to resolve the problem. We can interpret the parenthetical as applying to the whole sentence, 'It is not the case that John waved his hand.' In other words, now the speaker is claiming the whole sentence instead of the embedded phrase. Its scope and application are ambiguous, and so a parenthetical is not the same as the fictional 'to swave.'

Strong ifids stumble by overdetermining the meaning of an utterance. Green hopes to avoid this by building in a conditional (if there is a speech act, then...), yet his comparison of parentheticals with 'to swave' reveals his ambitious use of syntax. He notes a prior agreement, or theory, in which 'to swave' is taken to have a distinct force when spoken seriously. But however faithful speakers are, this prior agreement cannot guarantee that 'to swave' will hold this distinct force intact across all (serious) uses. It is not agreement over words that adds up to successful communication, but aligned passing theories. Parentheticals have the same issue. Green takes syntax to be more than syntax - to fix a speaker's intent. Syntax pigeonholes truth conditions as if sentences have a predetermined set of options. Green rightly observes how parentheticals mark a transformation in an utterance, but wrongly explains where the transformation comes from and how it happens. A speaker uses words in any way that expresses their intent to a hearer. And force is set from successful linguistic exchanges, not formulaic expressions.

Our theorists, like us, aim to illumine day-to-day conversation. Hearers assign beliefs and intentions to a speaker. An interpretation must assign belief and intention simultaneously and without relying on one or the other to avoid an impenetrable circle (Davidson [7, p. 111]). But Green holds intention constant to assign belief, then belief constant to assign intention. They are parsed in either order since there are words, such as parentheticals, that he takes to fix both. Take 'John swaved his hand.' If uttered seriously, a speaker believes that John waved his hand and intends to assert the belief. The qualification, 'seriously,' is less than helpful, though. Better to say that the verb, 'swave,' assumes a certain intent which then 
evokes a belief, or vice versa. Otherwise, we are left with a vague constant by which belief and intent are ascribed. There is the option that 'swave' is constant, but, as we noted, force concerns the use of words, not a special meaning. Davidson suggests preference as the constant for assigning belief and intention, ${ }^{23}$ but that is not pressing here. As soon as we admit that no word grounds ascriptions of intent and belief singly - that is, without seriousness, preference, or other ways of qualifying utterance - the spell breaks and weak ifids weaken. They assume a speech act has occurred along assumed lines of regularity that are unaccounted for.

Weak ifids are too weak to help us make sense of daily conversation. A parenthetical, Green claims, ensures at least one force among others. In complex speech acts the parenthetical need not evince the main force of the utterance, as in 'Tell me whether a vixen is a female fox, as I claim.' The force of an utterance may be underdetermined, as in the example, or overdetermined. Consider 'Do you think, as I claim, a vixen is a female fox?' To interpret 'a vixen as a female fox' as being asserted because it follows the parenthetical builds too much into the sentence. The question tawnes a more tentative commitment. Of course, the moment of uttering may suggest a speaker deeply believes a vixen is a female fox, and so the parenthetical rightly signals the assertoric belief. But that is the point. Much depends on the moment of utterance between speaker and hearer. Weak ifids offer little help in making sense of the whole utterance.

Davidson puts force within mood. Green links them with syntax. Their angles on mood and force differ, yet their arguments show that dealing with one brings in the other. As a result, we can use the three requirements for an adequate theory of mood to test weak ifids. To recall, a theory must preserve the relation between moods, ascribe meanings suitable and unique to a given mood, and must track the meaning of utterances. Our earlier problem was that the first two requirements prompt a sentential operator while the last bars all operators save truth-functional ones. A weak ifid has a truth condition that holds or fails to hold, similar to a mood setter. It transforms by attaching a mode of commitment to the rest of the sentence. The coupling of mode and sentence equals force. What of mood? On one hand, weak ifids are not part of a sentence's mood since they can be attached or removed with no loss. On the other hand, they cannot be attached to any sentence of any mood, nor is mood always left intact. Take the innocuous statement, "Is a vixen just a female fox, as I claim." Green allows an utterance to have many forces, so the utterance can ask and assert. ${ }^{24}$ That is not at issue. Despite surface grammar, we pose that both mood and force are up for grabs in this utterance. While a hearer cannot neglect the parenthetical, it hardly decides word meaning. The crux is that treating the parenthetical as a weak ifid arbitrarily limits its possible roles in the utterance. This will result whichever strip of syntax we define as a force indicating device, weak or strong. The device blurs the relation of mood and force.

\section{A variable for schemes}

Argumentation schemes are defeasible: hearers accept a conclusion given the evidence at hand, memory and experiences, the speaker, other hearers, at this moment for this reason, and (sometimes) for the sake of acting. One reason for this is the assumptions (or presumptions) on which an argument stands or falls. These arguments are also given in settings of limited knowledge. Another reason is that the presumptive inference rarely stands on the surface of conversation. It must be interpreted through a series of utterances. So argumentation schemes have defeasible interpretations. A speaker's words may be loose

\footnotetext{
${ }^{23}$ See Davidson [7, “Thought and Talk," pp. 155-170].

${ }^{24}$ Johnson recently called this illocutionary pluralism (Johnson [15]).
} 
with implicit premises or a tricky ordering. But there is more. When asked critical questions, a speaker's argument may seem to shift. This need not mean changed commitments or claim, though. Shifts in argument are a dynamic of conversation. One one hand, schemes guide how we formalize arguments in an exchange after the fact. On the other hand, they guide an exchange by giving form to what is said in arguing. Between these aims are the elusive and fragile utterances that speaker and hearer(s) exchange. It is now up to us to define a variable that enables argumentation schemes to locate the mood and force of utterances.

Pinning down word meaning hinders clean cut schematizing. But to compute arguments, the force of utterances must be dealt with. An implicit intuition, capacity, or claim blocks a translation of ordinary speech into a schema. The requirement for successful communication - the convergence of passing theories - presents the difficulty, yet there are cues that programmers and engineers are privy to. It is not an impossible task, but one with defeasible results. A speaker can always reply, "That is not what I meant," as every husband or wife knows, and we should take them seriously. That is, we are after why this is so and how it shapes the use of argumentation schemes. An adequate variable directs speakers, hearers, and theorists to the range of meanings given the mood and force of an utterance and, in this way, makes the force more explicit. It is formalizing for the sake of engaging in and navigating a conversation without prematurely giving the final word.

Take back up our case study, an advice column that we can easily imagine being spoken over a meal. Carolyn Hax advised a young woman with what looked like a disjunctive argument. The woman is bringing her boyfriend to a family wedding and cringes at the thought that someone will talk about a misplaced kiss. Hax advised,

The only way she will feel less anxious is if she gets out from under the weight of her secret, for good. Either she tells her boyfriend; breaks up with him and thereby renders the secret moot; or finds a way to release herself of the guilt and just accept what she did as the kind of stupid thing humans do and forgive herself for it (Hax [14]). ${ }^{25}$

Which words we stress change the argument type and conclusion. It looks like an argument from practical reasoning with three options, but there are some issues. The third option ("finds a way to release herself of guilt") may encompass the first pair. The phrase, "just accept," either is part of the third option, repeats the conclusion, or states the unique conclusion. In most cases, we argue, a scheme cannot be used apart from critical questions because arguments are rarely self-contained and explicit in conversation. It is not obvious which argument a speaker intends. Schemes require dialogue, that is, a process of questioning, and the relation of mood and force explains why.

So far, we have yet to see how mood and force relate or how they fit in our ideal model of successful communication. Davidson observes that force concerns the special use of words with an ordinary meaning, not a special meaning. In theory, non-indicatives express a transformation relative to their indicative likeness. Mood setters express, enact, and refer, which we said was too much ground for one term. We agree with Davidson's approach, but still muse over force ${ }^{26}$ Green explains force with grammar apart from mood. His use of illocutionary validity for assigning force is insightful, yet his weak ifids are less than helpful. We need an account that leaves Hax's advice unsettled due to ambiguity and a loose inference, while making sense of her words. Davidson is right that the force of an utterance is always marked in a provisional and defeasible way, but this requires us to infer beyond mood.

\footnotetext{
${ }^{25}$ Italics added.

${ }^{26}$ As well as the forces of indicatives.
} 


\subsection{Force setter}

Theorists must explain the transformative nature of force with the syntactic categories defined by mood. To do so, we propose force setters. After defining this concept and arguing for its use, we will return to argumentation schemes.

Davidson writes that a mood setter is an explicit mark. He means this in a purposely vague sense since 'mark' contains anything that tips off a hearer to a speaker's intent. Someone may say to another, "It is starting to snow," as a way of directing the hearer to close the window. Nothing in the sentence tells an anonymous observer that the speaker is telling the hearer to do anything. But if the observer knows the speaker and the hearer - id est, knows their relationship - the speaker commands the hearer with that sentence. To bring in Austin, there are explicit and implicit performatives. Certain words mark the act instead of enacting: 'I am getting married' said during a marriage ceremony differs from 'I do' spoken at the alter (Austin [2, Lecture V]). By paying attention to the effects of linguistic acts, we can define a variable for the force of an utterance conditionally. ${ }^{27}$ This marks the defeasibility of natural arguments.

As before, validity centers on a speaker, $S$, except force pairs with utterance,

$$
\psi(u) .
$$

We retain a variable for force because nearly identical utterances may differ as acts. Someone may mouth words, too. ${ }^{28}$ There is asymmetry between the force of an utterance and the sentence ascribed to a speaker. A non-trivial act of interpretation is required. We will come back to this in a moment. To recall, validity concerns a speaker's commitments to a given sentence under a given mode, or a chain of force/content pairs,

$$
\left\langle\Delta_{1} A_{1}, \ldots, \Delta_{n} A_{n}, \Delta B\right\rangle .
$$

If one pairing holds, then another sentence is held under the same mode (Green [11, p. 228]). Since mode is not mood, a speaker may commit themselves assertorically with an interrogative or imperative. Mode rightly picks out that force changes the meaning of a sentence. But mode is not all there is to force. To assert is not only to believe something assertorically. It is an action. Force concerns what we do with our words. Illocutionary validity assumes that the act of uttering is settled, which is fine if we build in the fragility of utterances' meaning. For this purpose, we propose force setters.

If the inference interprets an utterance, instead of a sentence, we come closer to the requirement of successful communication - that is, the convergence of passing theories. With force, that is key. However, we need to retain the indeterminacy that comes from the simultaneous ascription of meaning to words and beliefs to the speaker. To decide illocutionary validity, there is an inference of the following kind:

$$
\frac{\ldots \psi(u) \ldots}{f_{\Psi}^{\prime} S}
$$

A mood setter attaches to the sentence, $S$, which we will explain shortly. The force setter is $f^{\prime}$, which lacks its own content in the ascribed interpretation. Still, we need a variable to distinguish an otherwise

\footnotetext{
${ }^{27}$ In this way, too, we draw from Green's formalization of force indicators without committing ourselves to any given linguistic constant.

${ }^{28}$ Mouthing words, say.
} 
identical sentence that conveys the (nearly) same belief, though doing something distinct. A speaker can say, "A vixen is just a female fox," to answer a question, order someone else to be quiet, or question them. In each case, the speaker may believe a vixen is a female fox, and say as much. ${ }^{29}$ So we cannot secure an act with theory, yet we can illumine and assess an act. More on that soon.

What of mode? On our model, hearers and theorists alike do not infer from a speaker's commitments to a sentence under a mode. This is not the force of uttering per se. When rightly heard, we can assign the truth conditions of the speaker's sentence by picking out the force of uttering. This act is where successful communication converges. Mode enters the picture when we want to test whether we heard correctly or make sense of an exchange after the fact. Maybe we proffer a sentence that we think the speaker should be committed to under one mode and not another. For example, "Do zoologists call female foxes vixens," may tease apart supposition from assertion. Besides testing our interpretation, it is from assigned commitments under a mode that we frame an argumentation scheme. This does not track the inference from the act of uttering to a sentence with setters because an argumentation scheme concerns the inference from premise(s) to conclusion across utterances in an exchange. At issue are the claims held. By contrast, the inference of our model concerns the moment a speaker speaks and a hearer makes sense of her words. Schemes can help us (and a hearer) make sense of the claims at stake, and so obliquely near the speaker's intended meaning, but they cannot be inserted into the passing theories by which successful communication occurs. An utterance is a move only within theory. First, it is an act.

In the next section we develop how argumentation schemes work given our model. For now, suffice to say that they remain crucial aids for making sense of natural arguments, testing and strengthening them. One of their benefits is pushing speakers to make the force of their utterance more explicit so we know more precisely their claims. A second benefit is (presumptively) restraining the force of an utterance in light of its respective claim(s). But we have done little to motivate adding force setters to mood setters, nor have we said what happens to Davidson's notion in our model.

From the force of uttering - the premise - a hearer infers a force setter, mood setter, and a sentence. A force setter is not a special meaning appended to the sentence. All we have are truth conditions. Mood setters concern a syntactic transformation. Force setters mark an act that we theorize as a syntactic transformation. The words, 'It is snowing,' are not the same as the words just typed. Davidson seems keen to this limit for formalizing force, and so restricts himself to mood. But the formula does not output input. Rather, it draws out what is in play in conversation. The words uttered differ from the uttering, then the sentence we analyze must bring in the meaningfulness of the utterance. The force setter is an empty placeholder for the act of uttering in a given exchange. Added to the indicative core and mood setter are an assumed action that our theory interprets. The setter is not the force, which occurs by a speaker uttering the words in a certain way to a hearer with an intent for the hearer to understand those words accordingly. But the variable is not negligible. For one, it keeps a sentence at one remove from the uttering of a sentence. A theory geared to daily conversation must keep that distance in place. Also, force and mood may part in an utterance and that parting contribute to its meaning. What sets mood is explicit. Force less so. Unless we are prepared to give up standard grammatical moods, or cleave grammatical moods from semantic ones entirely, a variable is required for the forces a hearer ascribes to the speaker's uttering. ${ }^{30}$

\footnotetext{
${ }^{29}$ With the question, we can imagine the speaker first calling out someone who insulted a woman. The one who insulted might respond that a vixen is just a female fox. The utterance, "A vixen is just a female fox," questions the sincerity of the person who insulted. Endless cases like these can be imagined, which we seek to explain by our account.

${ }^{30}$ Id est, the way a hearer hears the speaker's words when that distinction inflects meaning.
} 
Force setters limit mood setters. Yet their limit contributes to meaning. In large part, our view agrees with Davidson. We merely unburden mood setter. It is no longer uttered, but is restricted to the decomposition of a successful exchange. That is, theorists take non-indicatives to be transformations relative to an indicative core. They are not actual transformations. And so there is only one speech act when non-indicatives, like 'Go' or 'Did he go,' are said. Mysterious is how the same words in the same grammatical mood differ in their transformation. If there is a different mood setter for each transformation, the traditional categories will not do. But we loose the difference if mood setters track traditional categories. We opt for the latter. Force setters capture the difference by standing in for how a hearer takes the speaker's act of uttering. Put differently, it is a variable for the act a speaker expressed by uttering and intended to express and the hearer's uptake. The variable is empty because it refers to what occurs in the moment of successful communication: to use the language from before, the convergence of passing theories. Included is what a speaker intends to do by uttering, which contributes to the meaning of the sentence uttered.

We differ from Davidson in what we take to be spoken. Neither a mood setter or force setter are spoken. Both are ascribed after the fact to make sense of a successful exchange. And so our view seems to fumble where Davidson's two simultaneous speech acts hold: non-indicators lose their truth value or their mood. Since a mood setter and a sentence have non-conjoined truth values, non-indicatives as a whole lack a truth value yet stay meaningful. We make an utterance one act and are left without an operator (remember, we only have truth-functional operators). Like Davidson, we hold that a speaker's use of words gives meaning, not the words divorced from their use. The meaning of an indicative and a non-indicative comes from the same place, and so a theory of mood and force best preserves a single act of uttering across moods. Instead of paring two acts from one, mood setters are a theoretical device for making sense of a unique linguistic act. Davidson is right to decompose non-indicatives into mood setter and sentence, but this occurs within a theory. It is a matter of specifying truth conditions, which does not require us to break up the act of uttering.

A force setter is hard to speak of, though it sounds more uncanny than it is. This is partly due to the persisting ambiguity of a speaker's intent: a speaker may always be insincere or speak in bad faith. A speaker can abuse language to manipulate or mislead a hearer. A force setter marks a speaker's reason and intent for speaking, and these propositional attitudes separate forces. Different forces have different purposes. So an assertion puts forward truth conditions, a question elicits an answer, a command prompts a hearer to do (or not do) something. Suffice to say, forces differ by the reason for uttering, and how it is intended to be heard and responded to. A force setter must be distinct enough to distinguish these acts, while loose enough to embody the many ways a speaker makes their intent known. For these reasons, a theory of action is required to offer a full interpretation of an utterance. ${ }^{31}$ We hope to show how such a theory will inform the use of argumentation schemes. And we have almost returned to these schemes. There remains the question: Why do moods lend themselves to certain uses?

Force swings loose of mood, yet moods lend themselves to certain uses. A speaker readily asserts with an indicative, asks with interrogatives, commands with imperatives. But none of the moods fix certain acts (not to mention these same acts do not require certain moods). The question is how susceptible forces are to moods. If moods are taken to have inherent uses, the apparent suitability of moods to use misleads. No doubt, the tendency results from facility of communication. Syntactic forms and regularities help speakers and hearers along. But these forms expand possible uses rather than confine them. ${ }^{32}$

\footnotetext{
${ }^{31}$ See Davidson [7, "Thought and Talk"] for a full argument.

${ }^{32}$ This follows from what Davidson calls the autonomy of linguistic meaning (Davidson [7]).
} 
If an imperative has set uses, it is an open set. Our suggestion is that moods lend themselves to certain uses because what we call their syntactic transformation makes the force of an utterance precise and effective. Sometimes, this happens by mismatching mood and force. Often not. Whatever the story is for why these grammatical forms emerged, a part of that story is convenience. It is easier to rely on widely accepted norms for asserting, asking, and commanding when speaking with a stranger. But this convenience does not get at the significance of a linguistic action. ${ }^{33}$

\subsection{Schemes for practical reasoning}

With a model for successful communication in hand, we argue that the mood/force relation makes natural arguments defeasible. Theorists come to successful exchanges after the fact. Schemes guide dialogue, supposing an argument type, inference, prompting questions or answers, and assessing, yet speakers speak meaningfully apart from these signposts. ${ }^{34}$ It remains to be shown how we can use schemes within our model.

1. Applying a scheme. Given our test case, we will focus on practical reasoning arguments. The major premise of a practical inference is the goal, the minor premise is the action to achieve the goal, and the conclusion is the normative umph (Walton et al. [42, p. 323]). Here, again, is the scheme for an argument from two-person practical reasoning (Walton [41], Waltonet al. [42]):

Premise 1: $X$ intends to realize $A$, and tells $Y$ this.

Premise 2: As $Y$ sees the situation, $B$ is a necessary (sufficient) condition for carrying out $A$, and $Y$ tells $X$ this.

Conclusion: Therefore, $X$ should carry out $B$ unless she has better reasons not to.

Now recall Hax's advice to the young woman. There are a few options for the goal (what the woman intends to realize). ${ }^{35}$ For Hax, the sister's goal is either to "feel less anxious" or "to release herself of the guilt" and/or "just accept" what she did. But, keeping in mind the situation, there are other options: for example, to get through the wedding without embarrassment. If so, then the final alternative differs from the first statement. If the sister steels herself or finds another way to bypass feelings of embarrassment, then she can go to the wedding without fear. Revelations of her past deed are irrelevant. This depends on how we interpret "just accept," too, since it seems to encompass the point of the first two options, and so suggests the action needed to relieve anxiety.

Which goal matters for constructing a schema. Suppose it is relieving anxiety. Then the minor premise consists in three actions, each of which singly satisfies the goal. We have the following:

- Major premise: The sister has the goal of relieving her anxiety over a secret.

- Minor premise: Telling the secret to her boyfriend $(A)$ would achieve the goal.

- Minor premise: Breaking up with her boyfriend $(B)$ would achieve the goal.

- Minor premise: Releasing herself from guilt, accepting her action, and forgiving herself $(C)$ would achieve her goal.

- Conclusion: She ought to do either $A, B$, or $C$ to achieve her goal.

\footnotetext{
${ }^{33}$ See Davidson's arguments concerning linguistic conventions (Davidson [7]).

${ }^{34}$ Said differently, the scheme does not set parameters for how an utterance is meaningful. We assume as much since speakers rarely, if ever, present an argument along clear-cut schematic lines.

${ }^{35}$ This is similar to the first critical question for a practical inference, except it is not about conflict between goals (ibidem). Here, interpreting the goal itself is in question.
} 
Fixing the goal does not clarify "just accept," which challenges our first pass at a schema. Hax seems to be saying more in her last option than the others. That is, the last option is more than an alternative to the first two. Hax may be stressing the last one and, if so, the above schema holds. She could also be stating what the sister must do to move on. If right, her list is not a disjunction for the same goal. We test a schema's adequacy by asking its critical questions. The fourth critical question that Walton, Reed, and Macagno (Walton et al. [42, p. 323]) list asks for the grounds on which the goal is possible. The second critical question asks about the plausibility of alternatives. But reading Hax's advice, the alternatives follow from or lead to the sister's acceptance of herself, not relief from anxiety. Hax writes in the third option, "finds a way to release herself," then with "just accept" describes what is needed regardless of what the sister does or does not do. Relieving herself of anxiety results from achieving the goal; it is not the final aim of Hax's advice.

But then, accepting her action may be the goal Hax is arguing for. This is the way to lighten the weight of her secret. There remain alternatives, yet the schema shifts as follows:

- Major premise: The sister has the goal of accepting her past action.

- Minor premise: Telling the secret to her boyfriend $(A)$ would achieve the goal.

- Minor premise: Breaking up with her boyfriend $(B)$ would achieve the goal.

- Minor premise: Finding another way to release herself of guilt $(C)$ would achieve the goal.

- Conclusion: She ought to do either $A, B$, or $C$ to achieve her goal.

The goal becomes an action and the alternatives enable her to do it. Hax stresses the final line to prompt the addressee to stress the same with her sister. It is the bottom line action that must be done. Again, the disjunctive form misleads. They are 'escapes' from doing what should be done. The normative umph coming from 'just accept' underlines not only the goal but all that needs to be done. And then we seem to be back at the first goal: when we ask about these alternatives, Hax means for the reader to see that the only viable option for relieving oneself of anxiety is accepting and forgiving oneself. She anticipates this with her first conditional ("The only way she will feel..."). The point is not that the sister accept her past action; it is for her to accept her action as a means of relieving anxiety. The anxiety is the problem to overcome. And so we return to the first goal and its ambiguities.

Maybe the problems come from false alternatives. We can streamline the practical inference to capture the sense of the stress, tone, and qualification. The alternatives become other options (answers to the third critical question) that pale in comparison. Here is the form:

- Major premise: The sister has the goal of relieving her anxiety over a secret.

- Minor premise: Accepting her past action will achieve this goal.

- Conclusion: She should accept her past action to achieve her goal.

Included in accepting her past action is forgiving herself for it. This seems to better express the inference at stake. Ambivalence still persists, and this is our main point. The phrase, "just accept," (basically) commands the addressee to to tell her sister to accept her past action. Hax issues a directive vicariously through the sister. If so, we may wonder if this is an argument from a practical inference rather than an argument from authority ${ }^{36}$ or argument from interaction of act and person (Walton et al. [42, p. 321]). Our doubt is due to the normative thrust of the inference coming from who the author is rather than an action. ${ }^{37}$ On the other hand, the sentence states all that needs to be done to meet the goal. It describes an action rather than tells anyone to do it. The final clause is an indicative like the others. And so the

\footnotetext{
${ }^{36}$ See argument from position to know or from expert opinion (Walton et al.[42, pp. 308-309]).

${ }^{37}$ Besides, just accepting oneself is a strange sort of act.
} 
argument's weight comes from the form: the action that must be done to meet an end. Even in this stripped form, in sum, the force remains undecided. As a result, so do the truth conditions.

Let us assume the argument is a practical inference to place "is just." If the final statement is an indicative, the adverb may have benign stress - it leaves the truth conditions alone. Or not. If an imperative, it may or may not change meaning. How we parse this word exemplifies the larger issue of how we interpret force. The claim from before returns: the mood/force relation is a reason for the defeasibility of natural arguments. The same words set a given utterance apart in one way, then in another when said by someone else in another time and place. By supposing an argument scheme, we isolate force ${ }^{38}$ with critical questions.

2. Using critical questions. When spoken to, a hearer must recognize the words and how the speaker says them. There is an endless list of other background knowledge and belief that may be required for, or clarify, the exchange. The inference from illocutionary validity concerned the sentence a hearer or theorist may ascribe to an utterance. Appended to the sentence are a mood setter and a force setter. Argumentation schemes indirectly handle the switch from utterance(s) to move(s). Whether a respondent reasons with them in mind or a theorist applies them to an exchange after the fact, they assume utterances are moves of certain sorts. A hearer may take a speaker's words in an unintended way, a speaker can misspeak, or a speaker reason out loud. Critical questions are means to navigate the vicissitudes of everyday conversation.

Macagno cites seven categories of action that orient the task: rapport building, information sharing, discovery, inquiry, persuasion, deliberation, negotiation (Macagno et al. [23, Table 1], Macagno [20, Fig. 2]). These can be ascribed by hearers or theorists as the force setter. Which is meant by Hax's declaration that the sister must "just accept" her action? Clearly, Hax is trying to persuade, but she could be persuading by stating the need to accept or by inferring means to ends. Or Hax could be negotiating. Out of the options she lists, it would be best for the sister to just accept her action. Given the situation, Hax publicly writes to the sister in such a way that the sisters could work out their options together or Hax herself could be negotiating with the options presented by the sister. Not to mention that these columns are meant to entertain other readers. But Hax may also deliberate toward a certain decision, the sister's decision to accept her action. Or, again, Hax could be establishing rapport by venting her frustration at the simple choice that needs to be made. Like Green's weak ifid, categories of action can only be loosely applied and they do not decide the force/mood relation. Still, hearers and theorists can be guided to the right critical questions and adjust by presuming a category.

Relevance depends on an utterance type given a dialogue goal, Macagno adds. The aim of a dialogue, however, differs from the force of a given utterance - one is locutionary force, the other illocutionary. While Macagno brings in lower and higher levels of dialogue goals, illocutionary force remains unaccounted for. Whether Hax's statement commands or declares, our interpretation seems to fit the goals we assigned to the advice column. Nor does the aim restrict the force of a given utterance. Someone can achieve the goal of having a door closed by asking someone else to close it, ordering them to, or describing the problems of leaving the door open. Macagno's approach to relevance, in short, assumes that a given speech act has occurred with a certain definiteness that has been left unexplained and intuitive. An utterance has been replaced by a sentence in his analysis.

Still, Macagno's criteria for encoding relevance is a useful starting point for dealing with the relation between mood and force. A series of yes or no questions leads to the presumption of relevance (or irrelevance) and sets its strength. The questions and their ordering assume an interpretation of the utterance's

\footnotetext{
${ }^{38}$ Or potential forces.
} 
force, yet test an interpretation of an otherwise ambiguous utterance. Here are the questions, then we will explain:

- Is $U$ [the utterance] coherent with the goal of the previous move(s)?

- Does $U$ address the Topic $x$ of the previous move(s)?

- Can $U$ be presumed to contribute to the point?

Further questions measure the strength of relevance. If we adopt a principle of charity in which we assume that, more often than not, a speaker speaks meaningfully, and so speaks relevantly to the matter at hand, ${ }^{39}$ then we can use relevance as a way for evaluating an interpretation. This is insufficient on its own, but in the case at hand it will help. Given its written form, Hax has constructed a string of sentences that cohere to a common goal. Their topic is the same and each sentence contributes to the aim (however we construe it). With this default, we can ask which interpretation optimizes relevance, and this will be the presumed interpretation from which an argumentation scheme can be constructed.

So $u$ stands in for "[she] finds a way to release herself of the guilt and just accepts what she did as the kind of stupid thing humans do and forgive herself for it." At issue is the force of this utterance (or inscription). And the represented sentence with a given mood setter and assumed force is inferred. Our proposal is that the suant inference defines a generative role for critical questions: ${ }^{40}$

$$
\frac{\ldots \psi(u) \ldots}{f_{\Psi}^{\prime} S}
$$

Since the author is absent, we cannot seek clarification. At best, the sisters can give a reasonable approximation of Hax's intended meaning. That is, they must suppose a certain force based on reasons. The ideal is that the sentence that replaces the original inscription (their interpretation) will share truth conditions. The sentence has a mood setter that shares the truth conditions, more or less. The statement will be relevant and, assuming that the overall argument is a practical inference, will result in the strongest argument. There are three steps:

1. Suppose content for the force setter (fix the speech act).

2. Pair the utterance with an indicative counterpart.

3. Articulate the resultant change of the indicative according to the mood setter.

An interpretation is defeasible insofar as future information (a second article by Hax, say, reading prior ones, or a phone call from her) may change which interpretation is more likely. And the relation between mood and force sustains defeasibility. Notice, too, that the force must be determined simultaneously with weighing the relevance, setting other variables like the goal of the discourse, the topic, and the statement's contribution, and identifying the argument type. This cannot be treated as a linear process, but one of mutual dependence. To illustrate, we will outline the inference given by two suppositions of Hax's advice.

Suppose, first, that the statement commands: $f$ ' represents the command of the original inscription. In place of the inscription, we have "The sister will accept her action" and then we ask how the mood setter changes the otherwise indicative sentence. The sister accepting her action in response to reading the piece makes the sentence true. The sister not accepting her action makes it false. We still have the

\footnotetext{
${ }^{39}$ More needs to be said on this principle, as we noted before.

${ }^{40}$ That is, the critical questions make the inference at stake more explicit.
} 
question of whether the prior options are alternatives, are conjoined to this command, or are rhetorical groundwork for the command. Sidelining that question, we have the practical inference from before:

- Major premise: The sister has the goal of relieving her anxiety over a secret.

- Minor premise: Accepting her past action will achieve this goal.

- Conclusion: She should accept her past action to achieve her goal.

The force of the utterance as it has been parsed in the theory is broken up into the minor premise and the conclusion. The indicative core appears in the minor premise and is framed as a means to achieve a goal. The force comes out in the conclusion. We can ask whether this further parsing of the statement aligns with the speaker's/writer's intent by asking critical questions. Compare the above supposition with another.

The statement may also state a claim so that $f$ ' represents the declaration. "The sister accepts her action" goes in place of the inscription with the stress of 'just' amounting to rhetoric. ${ }^{41}$ The sentence is true if the sister accepts her action, but not in response to Hax's directive. The truth of the statement is closely tied in to the means-ends inference of the argument: if the sister accepts her action, then she will relieve her anxiety. The normative weight of the conclusion does not come from the force of an inscription, but from the inference drawn. Glancing to the preceding paragraph, we see that the basic argument form works here, too, which might tempt us to treat the mood/force relation as negligible. But doing so blinds us to the defeasibility of the interpretation that the argument form assumes, which changes how we respond to the critical questions associated with the scheme.

Critical questions direct a speaker to make the intent more explicit by assuming an intent and testing the results. Below are the critical questions for practical reasoning. Notice how answers change if we take the statement in question as a command or as a declaration.

1. Does $X$ have other goals (of higher priority) that might conflict with the goal of realizing $A$ ?

2. Are there alternative means available to $X$ (other than $B$ ) for carrying out $A$ ?

3. Would carrying out $B$ have known side effects that might conflict with $X$ 's other goals?

4. Is it possible for $X$ to bring about $B$ ?

5. Are other actions, as well as $B$, required for $X$ to bring about $A$ ? (Walton et al. [42, p. 326])

If a command, the force of the advice falls on accepting a past action. If a declaration, the force falls on what will happen if she accepts her past action. Both schemes assume the same goal. ${ }^{42}$ Which we adopt changes how we answer any of the above critical questions. This is because the assumed force changes the commitments involved. Since the commitments change, so, too, will the inference at stake. Critical questions tease out other commitments that illumine what Hax intends as well as the sister's goal(s) and how she wants to obtain them. In this way, the dialogical use of scheme promote conversation and analysis. Through dialogue hearers and theorists circle around intention and force.

For formalizing and computation, the goal is a system for pairing sentences with modes, creating provisional sets for (even during) a dialogue, and testing utterances accordingly. This process recreates dialogical moves after the fact or follows a live dialogue. Dialogue type, topic, point, overall goal, basic claims in play, category of action, role of speaker and hearer(s), and other elements of setting (such as court procedure) set parameters. A sentence/mood pairing must be presumptively ascribed to an utterance since, if our argument is right, a move and an utterance are not identical. We cannot make the meaningfulness of an act of speaking altogether explicit, nor pin down its meaning for good. But

\footnotetext{
${ }^{41}$ That is, the adverb does not effect the truth conditions of the inscription.

${ }^{42}$ Which we have already seen can be disputed.
} 
robust networks of sentence/mood pairings enrich heuristic and evaluative capacities of a formalism, which brings $\mathrm{AI}$ into our daily conversations.

It is our hope that the analyses presented in this chapter, at a minimum, bring to light the role that force and defeasibility play in language pragmatics. Understanding such roles is crucial to future work in artificial intelligence, particularly the subfields of natural language processing, understanding, and generation. Without the ability to understand the nuances of mood/force in language, future AI will be unable to interpret open-textured terms in rules at all levels, including laws, commands, and codes of ethics (Prakken [27], Licato and Marji [18], Quandt and Licato [28]). And the proper interpretation of open-textured terms is a necessity for autonomous agents, if we want them to operate in the real world under a set of human-understandable laws.

Grammar and other regularities cannot be our sole reliance when making sense of speakers. Doing so minifies natural arguments' defeasibility. In the first section of this paper, we showed the elusiveness of everyday speech with Davidson's ideal model for successful communication. His model enabled a first pass at mood and force. Then, we took up his mood setter to argue that mood and force cannot be tagged on to syntax. We were less sure about mood setter's heavy theoretical role in Davidson's account and the view that a speaker says a setter so we turned to Green's weak illocutionary force indicating devices. He uses illocutionary validity to track force, but his device was less directive than it seems. So we dropped his device for what we call force setters, a limiting variable that refers to the act assumed by a given interpretation. The term theorizes mood and force, rather than one or the other singly, by attaching the syntactic transformation in mood to a speaker's assumed act. The speaker's act is presumed by a hearer or theorist. How we take the speaker's act changes the meaning of the syntactic transformation (mood setter). In this way, force setters pair with mood setters and sentences to decide meaning. Although the mood/force relation exposes the depth and import of defeasibility in everyday exchanges, critical questions help hearers and theorists make sense of a speaker's claims. They do so by engendering discussion, not expediting the 'final word.' In this way, critical questions serve as heuristics for involving AI systems in dialogue. With Walton's schemes, a speaker's force can be made explicit (enough) and the exception-filled ways humans use language adapted to.

\section{References}

[1] J.D. Atlas, Presupposition, in: L. Horn and G. Ward, eds, Blackwell Publishing, Ltd., Oxford, 2008, Chapter 2.

[2] J.L. Austin, How to do things with words, in: J.O. Urmson, ed., Oxford University Press, Oxford, 1962.

[3] R. Brandom, Making It Explicit: Reasoning, Representing, and Discursive Commitment, Harvard University Press, Cambridge, 1994.

[4] A. Capone, Further reflections on semantic minimalism: Reply to Wedgwood, in: A. Capone, F. Lo Piparo and M. Carapezza, eds, Springer, Cham, 2013, pp. 437-473.

[5] A. Capone, Introducing the notion of the pragmeme, in: A. Capone, K. Allan and I. Kecskes, eds, Springer, Dordrecht, 2017, Chapter Introduction.

[6] M. Dascal, Interpretation and Understanding, John Benjamins Publishing Company, Amsterdam, 2003.

[7] D. Davidson, Inquiries into Truth and Interpretation, Clarendon Press, Oxford, 2001.

[8] D. Davidson, Truth, Language, and History, Clarendon Press, Oxford, 2005.

[9] C. Dorr, To be F is to be G, Philosophical Perspectives 30 (2016), 39-134. doi:10.1111/phpe.12079.

[10] M. Dummett, The Seas of Language, Oxford University Press, Oxford, 1996.

[11] M.S. Green, On the autonomy of linguistic meaning, Mind 106(422) (1997), 217-243. doi:10.1093/mind/106.422.217.

[12] H.L.A. Hart, The Concept of Law, Clarendon Press, Oxford, 1961.

[13] A. Hasting, A reformulation in the modes of reasoning in argumentation, Dissertation, Northwestern University, Evanston, 1963. 
[14] C. Hax, A kiss is just a kiss, but secrets can be relationship poison ,2020. https://www.washingtonpost.com/lifestyle/ advice/carolyn-hax-a-kiss-is-just-a-kiss-but-secrets-can-be-relationship-poison/2020/06/12/f551bee2-a1f2-11ea-95901858a893bd59_story.html.

[15] C.R. Johnson, Investigating illocutionary monism, Synthese 196 (2019), 1151-1165. doi:10.1007/s11229-017-1508-7.

[16] M. Kissine, From Utterances to Speech Acts, Cambridge University Press, Cambridge, 2013.

[17] G.N. Leech, The Principles of Pragmatics, Longman, London, 1983.

[18] J. Licato and Z. Marji, Probing formal/informal misalignment with the loophole task, in: Proceedings of the 2018 International Conference on Robot Ethics and Standards (ICRES 2018), 2018.

[19] F. Macagno, Assessing relevance, Lingua 210-211 (2018), 42-64. http://www.sciencedirect.com/science/article/pii/ S002438411730517X. doi:10.1016/j.lingua.2018.04.007.

[20] F. Macagno, Coding relevance, learning, culture and social interaction, Learning, Culture and Social Interaction (2019). doi:10.1016/j.lcsi.2019.100349.

[21] F. Macagno and A. Capone, Uncommon ground, Intercultural Pragmatics 13(2) (2016), 151-180. doi:10.1515/ip-20160007.

[22] F. Macagno and D. Walton, Interpreting Straw Man Argumentation: The Pragmatics of Quotation and Reporting, Springer, Amsterdam, 2017.

[23] F. Macagno, D. Walton and G. Sartor, Pragmatic maxims and presumptions in legal interpretation, Law and Philosophy 37(1) (2018), 69-115. doi:10.1007/s10982-017-9306-4.

[24] D.N. MacCormick and R.S. Summers, Interpreting Statutes: A Comparative Study, Routledge, 1991.

[25] A. Marmor, The Language of Law, Oxford University Press, Oxford, 2014.

[26] E. Oishi, Austin's speech acts and Mey's pragmemes, in: A.K. Capone and I. Kecskes, eds, Springer, Dordrecht, 2017, pp. 335-350.

[27] H. Prakken, On the problem of making autonomous vehicles conform to traffic law, Artificial Intelligence and Law 25(3) (2017), 341-363. doi:10.1007/s10506-017-9210-0.

[28] R. Quandt and J. Licato, Problems of autonomous agents following informal, open-textured rules, in: Human-Machine Shared Contexts, W.F. Lawless, R. Mittu and D.A. Sofge, eds, Academic Press, 2020.

[29] W.V.O. Quine, Word and Object, M.I.T. Press, 1960.

[30] G. Sartor, D. Walton, F. Macagno and A. Rotolo, Argumentation schemes for statutory interpretation: A logical analysis, in: Legal Knowledge and Information Systems (Proceedings of JURIX 14), 2014, pp. 21-28.

[31] M. Sbisà, Speech acts in context, Language Communication 22(4) (2002), 421-436. doi:10.1016/S0271-5309(02) 00018-6.

[32] J. Searle and D. Vanderveken, Foundations of Illocutionary Logic, Cambridge University Press, Cambridge, 1985.

[33] D. Sperber and D. Wilson, Relevance: Communication and Cognition, 2nd edn, Wiley-Blackwell, Oxford, 1995.

[34] R. Stalnaker, Common ground, Linguistics and Philosophy 25 (2002), 701-721. doi:10.1023/A:1020867916902.

[35] P.F. Strawson, Intention and convention in speech acts, Philosophy Review 73(4) (1964), 439-460.

[36] J. Streeck, Speech acts in interaction: A critique of searle, Discourse Processes 3(2) (1980), 133-153.

[37] R.S. Summers, Form and Function in a Legal System: A General Study, Cambridge University Press, 2006. ISBN 9780521857659.

[38] A. Tarski, The semantic conception of truth, in: H. Feigl and W. Sellars, eds, Appleton-Century-Crofts, New York, 1949, Chapter 3.

[39] S.E. Toulmin, The Uses of Argument, Cambridge University Press, Cambridge, 1958.

[40] D. Walton, Argumentation Schemes for Presumptive Reasoning, Lawrence Erlbaum Associates, Mahwah, NJ, 1996.

[41] D. Walton, Appeal to Expert Opinion, Pennsylvania State University Press, University Park, 1997.

[42] D. Walton, C. Reed and F. Macagno, Argumentation Schemes, Cambridge University Press, 2008.

[43] D. Walton, G. Sartor and F. Macagno, An argumentation framework for contested cases of statutory interpretation, Artificial Intelligence and Law 24 (2016), 51-91. doi:10.1007/s10506-016-9179-0. 